\title{
INTS6/DICEI inhibits growth of human androgen-independent prostate cancer cells by altering the cell cycle profile and Wnt
} signaling

\author{
Stephanie Filleur*1,2, Jennifer Hirsch ${ }^{1}$, Aline Wille ${ }^{3}$, Margarete Schön ${ }^{4}$, \\ Christian Sell ${ }^{5}$, Michael H Shearer ${ }^{2}$, Thomas Nelius ${ }^{1}$ and Ilse Wieland ${ }^{3}$
}

\begin{abstract}
Address: ${ }^{2}$ Texas Tech University Health Sciences Center, Department of Urology, Lubbock, TX, USA, ${ }^{2}$ Texas Tech University Health Sciences Center, Department of Microbiology and Immunology, Lubbock, TX, USA, ${ }^{3}$ Institute for Human Genetics, Otto-von-Guericke University, Magdeburg, Germany, ${ }^{4}$ Rudolf Virchow Center, DFG Research Center for Experimental Biomedicine and Department of Dermatology, University of Würzburg, Würzburg, Germany and ${ }^{5}$ Department of Pathology, Drexel University College of Medicine, Philadelphia, PA, USA

Email: Stephanie Filleur* - stephanie.filleur@ttuhsc.edu; Jennifer Hirsch - jennifer.marable@ttuhsc.edu; Aline Wille - aline.wille@med.ovgu.de; Margarete Schön - margarete.schoen@med.uni-goettingen.de; Christian Sell - csell@drexelmed.edu;

Michael H Shearer - michael.shearer@ttuhsc.edu; Thomas Nelius - thomas.nelius@ttuhsc.edu; Ilse Wieland - ilse.wieland@med.ovgu.de

* Corresponding author
\end{abstract}

Published: II November 2009

Cancer Cell International 2009, 9:28 doi:10.1 186//475-2867-9-28

This article is available from: http://www.cancerci.com/content/9/1/28

(c) 2009 Filleur et al; licensee BioMed Central Ltd.

This is an Open Access article distributed under the terms of the Creative Commons Attribution License (http://creativecommons.org/licenses/by/2.0), which permits unrestricted use, distribution, and reproduction in any medium, provided the original work is properly cited.
Received: II September 2009

Accepted: II November 2009

\begin{abstract}
Background: The gene encoding integrator complex subunit 6 (INTS6), previously known as deleted in cancer cells I (DICEI, OMIM 60433I) was found to be frequently affected by allelic deletion and promoter hypermethylation in prostate cancer specimens and cell lines. A missense mutation has been detected in prostate cancer cell line LNCaP. Together, these results suggest INTS6/DICEI as a putative tumor suppressor gene in prostate cancer. In this study, we examined the growth inhibitory effects of INTS6/DICEI on prostate cancer cells.

Results: Markedly decreased INTS6/DICEI mRNA levels were detected in prostate cancer cell lines $\mathrm{LNCaP}$, DUI 45 and PC3 as well as CPTXI532 as compared to a cell line derived from normal prostate tissue, NPTX1532. Exogenous re-expression of INTS6/DICEI cDNA in androgenindependent PC 3 and DUI 45 cell lines substantially suppressed their ability to form colonies in vitro. This growth inhibition was not due to immediate induction of apoptosis. Rather, prostate cancer cells arrested in GI phase of the cell cycle. Expression profiling of members of the Wnt signaling pathway revealed up-regulation of several genes including disheveled inhibitor CXXC finger 4 (CXXC4), frizzled homologue 7 (FZD7), transcription factor 7-like I (TCF7LI), and down-regulation of cyclin DI.
\end{abstract}

Conclusion: These results show for the first time a link between INTS6/DICEI function, cell cycle regulation and cell-cell communication involving members of the Wnt signaling pathway.

\section{Background}

Prostate cancer is the most common malignancy and the second leading cause of cancer-related death in men from western countries. The American Cancer Society (ACS) estimated for 2009, 192,280 new cases of prostate cancer in the United States with approximately 27,360 cases end- 
ing in death (ACS, Cancer statistics, 2009). Although these numbers reflect the recent progress in prostate cancer therapy, they also reveal the demand for more effective therapeutic strategies.

Progression of prostate cancer to androgen-independence has been associated with multiple molecular mechanisms such as androgen receptor (AR) gene amplification, $A R$ gene mutations resulting in AR hypersensitivity or change of AR specificity, involvement of coregulators, ligand independent activation of the AR, and involvement of tumor stem cells [1]. More recently, other androgen-independent mechanisms involving dysregulation of several cell-survival signaling pathways in androgen-independent prostate cancer have also been established. Deleted In Cancer 1 (INTS6/DICE1) gene (OMIM 604331) was identified to colocalize with the microsatellite marker D13S284 in 13q14.3, a region frequently affected by allelic deletion in many solid tumors including prostate cancer [2-5]. INTS6/DICE1 missense mutations have been previously detected in lung and prostate cancer cell lines NCI-H2126 and LNCaP respectively, and reduced INTS6/DICE1 expression appears to be associated with $\mathrm{CpG}$ promoter hypermethylation in lung and prostate cancer cells [3,57]. DICE1 is a $100 \mathrm{kD}$ widely expressed and highly conserved nuclear protein with predicted protein motifs reminiscent of classical DEAD box helicases suggesting its involvement in important nuclear functions such as DNA repair, transcription or RNA splicing [2,3,8]. In agreement with its nuclear localization, human DICE1 was detected to be subunit 6 of the integrator complex (INTS6) involved in small nuclear RNA processing [9]. This integrator complex is competent for transcription and may be recruited to the promoter of RNA polymerase II-dependent genes. Recently, INTS6/DICE1 has been identified as one of the target genes of CCAAT enhancer binding protein delta (C/EBPS) which is highly expressed in growth arrested, contact inhibited mammary epithelial cells [10]. INTS6/DICE1 is also subject to regulation by the tumor suppressor CDC73 that is mutually inactivated in hereditary and sporadic parathyroid tumors [11]. In mouse, the INTS6/DICE1 homologue interfered with the response to insulin-like growth factor 1 (IGF-1), and mouse and human DICE1 cDNA suppressed anchorage-independent growth of transformed mouse cells $[12,13]$. These results suggest that INTS6/DICE1 is a tumor suppressor gene and emphasize the need to better characterize its function.

\section{Results \\ INTS6IDICEI mRNA expression is down-regulated in prostate cancer cells}

In order to reinforce DICE1 tumor suppressor function in prostate cancer, we analyzed its expression in different human androgen-dependent/-sensitive (LNCaP), androgen-independent/-insensitive (DU145, PC3, PC3-ml); and prostate cell lines isolated from prostatic primary tumor (paired normal/tumor 1532NPTX/1532CPTX cell lines) [14]. Northern blot showed that DICE-1 mRNA in all the prostate tumor cell lines tested is strongly downregulated or undetectable compared to normal immortalized prostate 1532NPTX cells and BALB/c3T3 mouse cells transfected with the full length DICE1 CDNA (Figure 1).

\section{Exogenous expression of DICEI inhibits the clonogenic formation capacity of androgen-independent cell lines through an apoptosis-independent pathway}

DICE1 function in prostate cancer was studied by exogenously re-expressing DICE1 cDNA in the prostate tumor cell lines PC3 and DU145. This experiment was performed by transfecting the cancer cells with the pDICE1EGFP fusion construct or pEGFP control expression plasmid (Figure 2a, left). Synthesis of a DICE1-EGFP fusion protein in PC3 (Figure 2a, right) and DU145 (data not shown) transfected cells was shown by a band around 150

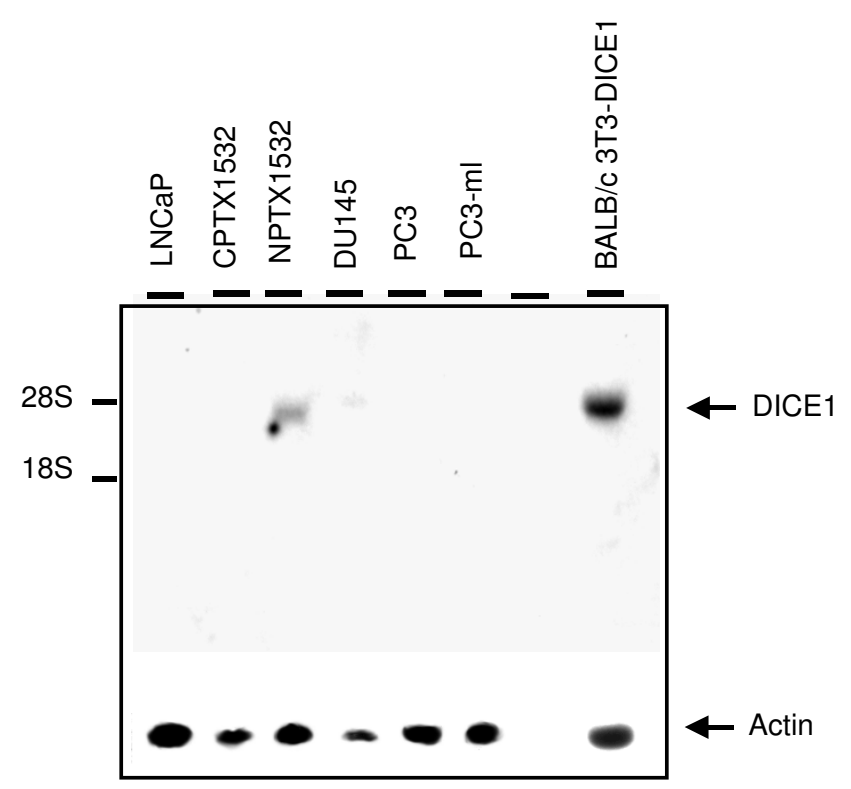

\section{Figure I}

Northern blot of prostate cancer cell lines. LNCaP, DUI45, PC3, PC3-ml and CPTXI532 and NPTXI532 (cells derived from cancer and normal prostate tissue) were analyzed using a full length DICEI cDNA as a hybridization probe. BALB/c 3 T3 cells transduced by full length DICEI CDNA were used as a positive control. The position of DICEI mRNA is indicated by an arrow on the right side and the positions of the I8S and 28S RNA are indicated by the hash marks on the left side. In the lower panel the same blot was subsequently probed for beta actin as a control for the relative amount of RNA in each sample. Note that two distinct batches of mRNA were collected from prostatic cell lines and gave similar expression profile for DICEI mRNA. 
A

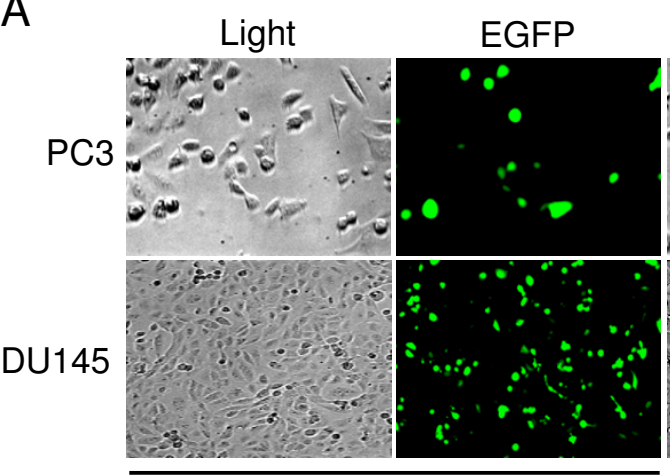

pEGFP
Light

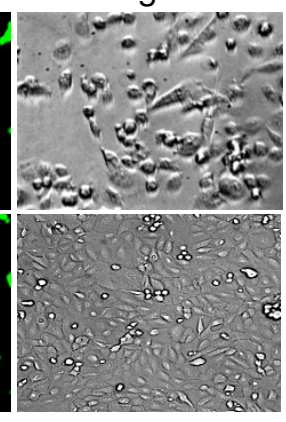

pDICE1-EGFP
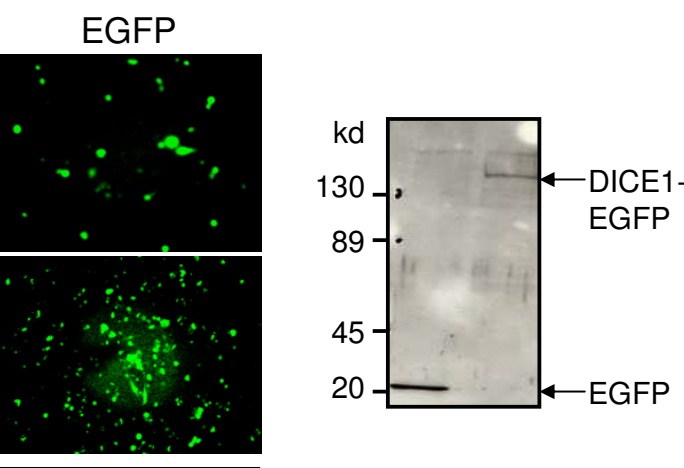

B
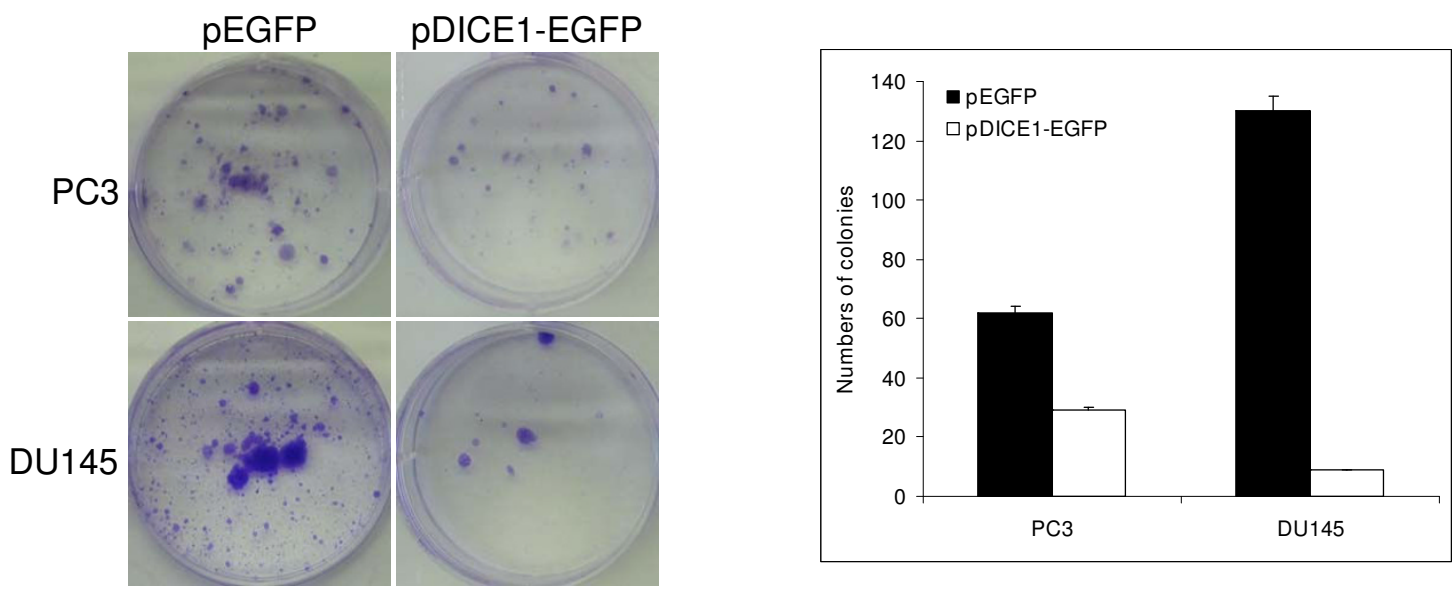

Figure 2

Inhibition of colony formation of PC3 and DUI 45 prostate cancer cells by PDICE I-EGFP fusion construct. PC3 and DUI 45 cells were transiently transfected with the pEGFP or PDICEI-EGFP fusion constructs. A. Equivalent transfection efficiencies (30-40\%) at 48 hours post-transfection were verified by reporting EGFP in situ fluorescence on the total number of cells (regular light) using an inverted microscope (left). Expression of constructs was analyzed in PC 3 cells by Western blotting of EGFP and DICEI-EGFP fusion protein using an anti-GFP monoclonal antibody (right). Sizes in kilodalton (kD) are indicated on the left. B. After transfection, prostate cancer cells were selected over 2-3 weeks in the presence of G4/8 antibiotic and stained with $0.5 \%$ crystal violet in methanol (left). Quantitative analysis of inhibition of the colony formation in PC3 and DUI 45 cells transfected with pEGFP and pDICEI-EGFP plasmid (right).

$\mathrm{kD}$ by Western blot analysis. This size is slightly larger than the calculated size (expected $\sim 125 \mathrm{kD}$ ). Similarly, a slightly larger than expected size band was previously found for human endogenous DICE1 protein functioning as integrator subunit 6 of the integrator multiprotein complex [9].

Transfected cells were then tested for their ability to form colonies in vitro in G418 supplemented selective medium. Interestingly, we show that the re-expression of DICE1 inhibits colony formation of PC3 and DU145 cells by $50 \%$ and $90 \%$ respectively when compared to the control
pEGFP-transfected cells (Figure 2b). With the androgendependent cell line LNCaP, previously shown to harbor missense mutation D546G in the DICE1 gene [6], we obtained inconsistent results concerning the growthinhibitory responses to DICE1-EGFP (data not shown).

To determine if DICE1 suppresses prostate cancer cell growth by inducing apoptosis, we analyzed its capacity to stimulate genomic DNA fragmentation in PC3 cells. PC3 cells were transiently transfected with pDICE1-EGFP or pEGFP plasmid. Subsequently, genomic DNA was extracted after 24 and 48 hours, quantified and loaded on 
an agarose gel. We could not detect any DNA fragmentation in PC3 transfected cells as compared to the apoptotic positive control cells (data not shown). These results were validated by loading higher amounts of genomic DNA (up to $10 \mu \mathrm{g}$, data not shown). In our understanding, the absence of an apoptotic signal could not be explained by a lack of sensitivity of the present assay. Indeed, we estimated approximately 30\% transfection efficiency in this experiment, which is an adequate ratio to visualize DNA fragmentation. Additionally, we tested the capacity of DICE1 to induce necrosis in androgen-independent cells. As expected, this analysis performed by propidium iodide (PI) uptake assay on prostate cancer cells did not show any significant effect of DICE1 expression on the percentage of PI-positive cells (data not shown). In conclusion, our results suggest that DICE1 is inhibiting prostate cancer cell growth through an apoptosis- and necrosis-independent pathway.

\section{DICEI expression induces GI arrest in androgen- independent cell lines}

To further understand the mechanisms involved in DICE1 growth inhibitory function, we examined the capacity of DICE1 to modify the cell cycle distribution of normal prostate cells RWPE-1 and prostate cancer cells LNCaP, PC3 and DU145. Similar to results obtained with normal RWPE-1 cells, re-expression of DICE1 in PC3 or DU145 cells induced a 30-50\% cell reduction in the sub-G0 phase (15.1 +/- 0.52 for pEGFP-PC3 versus $10.4+/-0.54$ for pDICE1-EGFP-PC3 and 28.4 +/- 2.21 for pEGFP-DU145 versus $14.9-/+1.18$ for pDICE1-EGFP-DU145), validating our hypothesis of an apoptosis-independent mechanism (Figure 3a-b). Likewise, the percentage of PC3 and DU145 cells in G0/G1 was increased about 20-30\% following DICE1 re-expression suggesting a block in the G1phase of the cell cycle (Figure 3a; $47.5+$ +- 0.23 for pEGFPPC3 versus 55.3 +/- 2.26 for pDICE1-EGFP-PC3 and 36.4
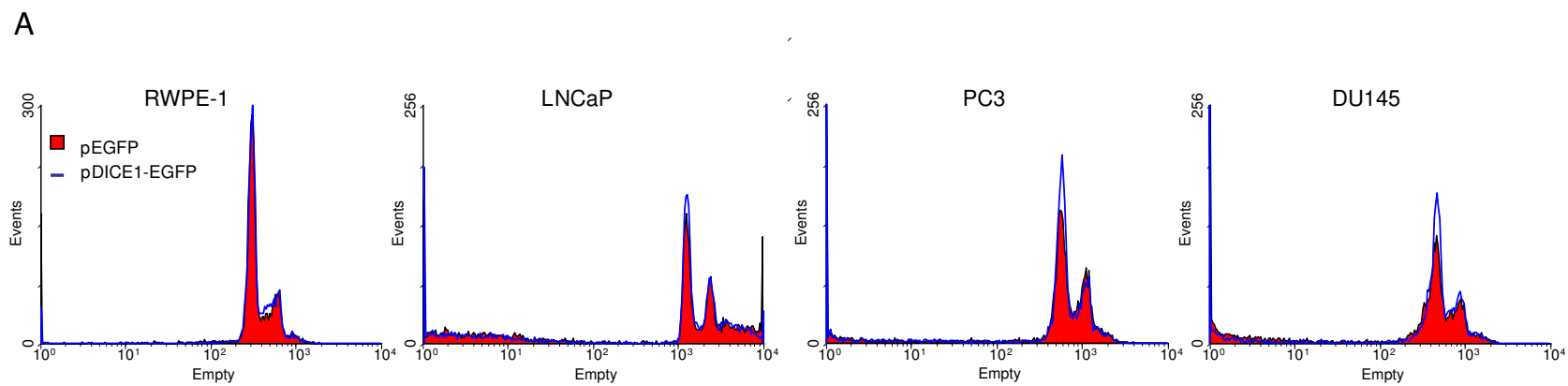

B

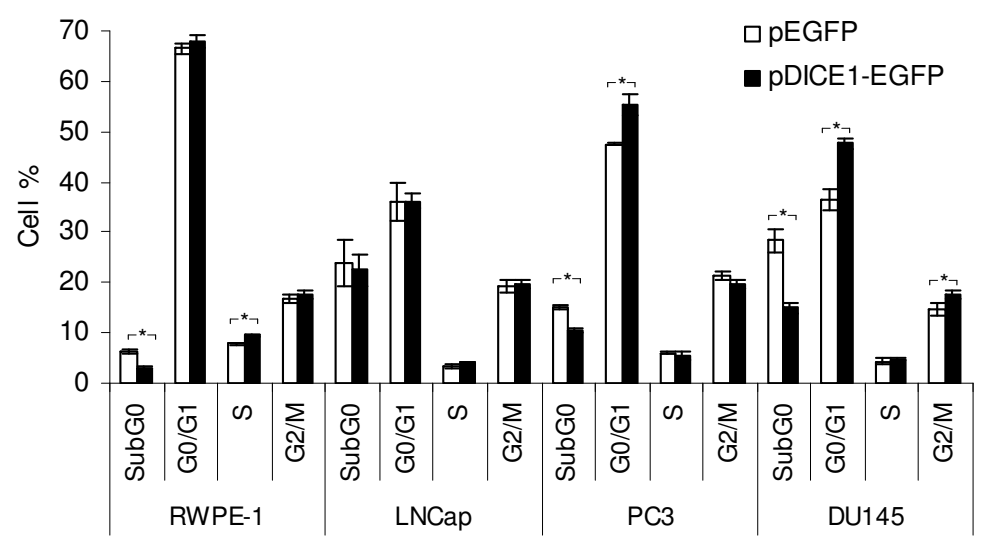

Figure 3

Cell cycle distribution in response to INTS6IDICEI re-expression. A. Normal prostate (RWPE-I) and cancer prostate (LNCaP, PC3 and DUI45) cells were transfected with pEGFP or pDICEI-EGFP expression plasmid, stained with propidium iodide and the DNA content was analyzed by flow cytometry. B. Quantification of flow cytometry analysis of DNA content. Results are represented as the average values +/- SD calculated from three separate experiments. *: $P<0.05$. Note the increase in the GI cell population in PC3 and DUI45 cells expressing PDICEI-EGFP compared to pEGFP cancer cells. 
+/- 2.24 for pEGFP-DU145 versus $47.6+/-1.0$ for pDICE1-EGFP-DU145). DU145 cells re-expressing DICE1 showed an additional 20\% increase in cell number in G2/ $M$ phase emphasizing that DICE-1 could regulate the cell cycle at different levels. In agreement with the results obtained in the colony formation assay, the re-expression of DICE1 in LNCaP cell line did not present any significant effect on their cell cycle distribution.

\section{Changes in the Wnt signaling pathway in response to DICE I}

As previously described, inhibition of the Wnt pathway in PC3 cells resulted in decreased colony formation in soft agar and in vivo tumor growth [15]. Therefore, we analyzed the expression of genes related to this pathway by PCR array. PC3 cells containing the exogenous pDICE1EGFP fusion construct showed differences in the expression of several genes when compared with pEGFP-trans- fected PC3 cells indicating regulation of Wnt signaling in response to exogenous DICE1 expression (Table 1). In particular, genes like CXXC finger 4 (CXXC4), frizzled homolog 7 (FZD7) and transcription factor 7-like 1 (TCF7L1) showed an up-regulation of more than 3- to 7fold, whereas cyclin D1 and transcription factor 7 (TCF7) were clearly down-regulated (3.8 and 3.6 fold, respectively; Table 1). To confirm the PCR array results, we repeated the expression analysis by quantitative real-time PCR for selected genes CXXC4, TCF7L1 and CCND1 in DICE1 - and control-transfected PC3 and DU145 cells. The data showed a clear 3.5 fold up-regulation of TCF7L1 in PC3 and DU145 cells in response to DICE1, whereas CCND1 was down-regulated (1.7 and 5.3 fold, respectively). In the case of CXXC4, DICE1-transfected PC3 cells showed a more than 30-fold up-regulation, whereas a 7 fold down-regulation was observed in DU145 cells (Figure 4).

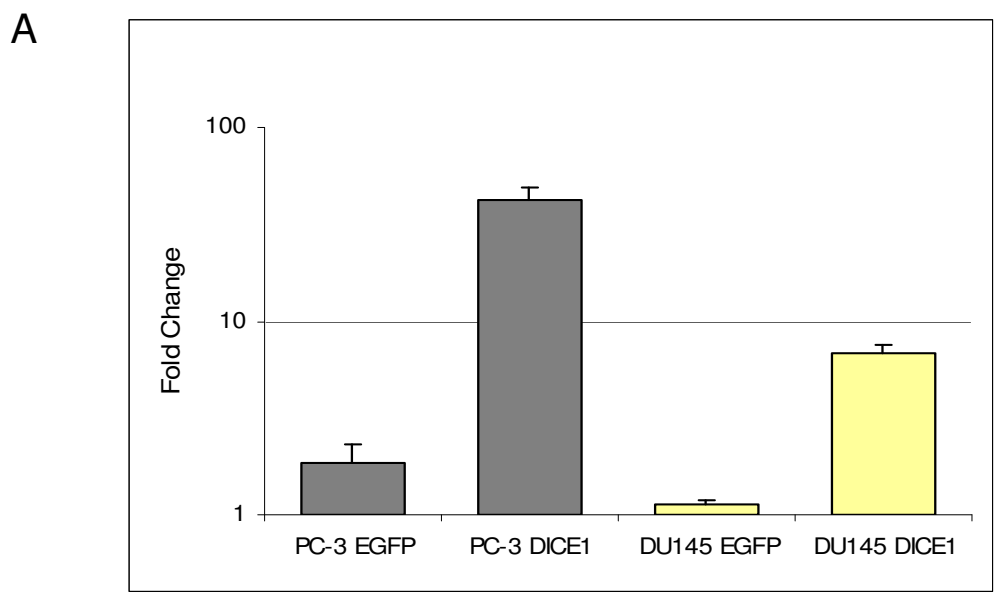

B

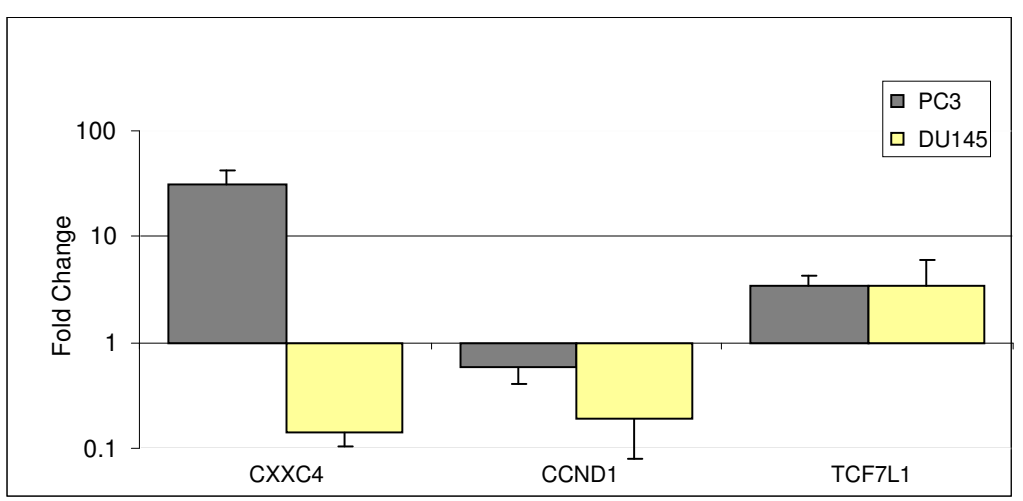

\section{Figure 4}

Real-time PCR of INTS6IDICEI responsive genes. A. Up-regulation of INTS6/DICEI expression in PC3 and DUI45 cells 48 hours post-transfection with DICEI-EGFP fusion construct (DICEI) or EGFP vector (EGFP) as control. B. Selected INTS6/ DICEI responsive genes of the Wnt signaling pathway, CXX finger 4 (CXXC4), cyclin DI (CCNDI) and transcription factor 7like I (TCFLI) monitored 48 hours after exogenous DICEI expression in PC3 and DUI 45 cells. The fold change in gene expression was determined by the comparative $\mathrm{C}(\mathrm{T})$ method using G3PDH as reference. 
Table I: Expression profiling of Wnt signaling pathway in INTS6IDICEI transfected PC3 cells

\begin{tabular}{|c|c|c|c|}
\hline Gene Symbol & Description & GenBank & FC \\
\hline \multicolumn{4}{|c|}{ Upregulated genes ${ }^{\mathrm{a}}$} \\
\hline AXINI & Axin I & NM 003502 & 2.14 \\
\hline СTBP2 & C-terminal binding protein 2 & NM 022802 & 2.14 \\
\hline $\mathrm{CXXC4}$ & $\mathrm{CXXC}$ finger 4 & NM 025212 & 7.5 \\
\hline FZD7 & Frizzled homolog 7 (Drosophila) & NM 003507 & 4.0 \\
\hline JUN & Jun Oncogen & NM 002228 & 2.8 \\
\hline MYC & V-myc myelocytomatosis viral oncogen homolog (avian) & NM 002467 & 4.0 \\
\hline SLC9A3RI & Solute carrier family 9 (sodium/hydrogen exchanger) & NM 004252 & 2.64 \\
\hline $\mathrm{T}$ & $\mathrm{T}$, brachyury homolog (mouse) & NM 003181 & 2.3 \\
\hline TCF7LI & Transcription factor 7-like I (T-cell specific, HMG-box) & NM 031283 & 3.24 \\
\hline TLE & Transcucin-like enhancer of split (E(spl)homolog, Drosophila & NM 005077 & 2.14 \\
\hline WISPI & WNTI inducible signalling pathway protein & NM 003882 & 3.24 \\
\hline WNT3 & Wingless-type MMTV integration site family, member 3 & NM 030753 & 2.3 \\
\hline WNT5B & Wingless-type MMTV integration site family, member 5B & NM 032642 & 3.5 \\
\hline \multicolumn{4}{|c|}{ Downregulated genes ${ }^{b}$} \\
\hline APC & Adenomatosis polyposis coli & NM 000038 & -2.5 \\
\hline BTRC & Beta-transducin repeat containing & NM 033637 & -2.7 \\
\hline CCNDI & Cyclin DI & NM 053056 & -3.8 \\
\hline FBXW2 & F-box and WD repeat domain containing 2 & NM 012164 & -3.3 \\
\hline FZD6 & Frizzled homolog 6 (Drosophila) & NM 003506 & -2.5 \\
\hline SENP2 & SUMOI/sentrin/SMT3 specific peptidase 2 & NM 021627 & -2.3 \\
\hline TCF7 & Transcription factor 7 (T-cell specific, HMG-box) & NM 003202 & -3.6 \\
\hline
\end{tabular}

a: FC, fold change $>2$, b: FC, fold change $<0,5$

\section{Discussion}

Previous studies provided functional evidence that the INTS6/DICE1 gene acts as a tumor suppressor gene [13]. Regarding prostatic tumorigenesis, INTS6/DICE1 expression is down-regulated in multiple prostate cancer cell lines as compared to normal prostate cells, and its exogenous re-expression in cancer cells leads to inhibition of their capacity to form colonies in vitro. However, few results exist on the molecular mechanisms involved in INTS6/DICE1 growth-inhibitory function. In a mouse tissue culture model with IGF-IR transformed Balb/c 3T3 cells, it has been shown that mouse and human DICE1 cDNA inhibit anchorage-independent growth $[12,13]$. These results suggested a link between the IGF-IR signaling system and DICE1 function. Anchorage-independent growth, suppression of apoptosis, cell migration, invasion and metastasis are particularly abolished in mouse tumor cells by mutational changes of tyrosine residues 1250 and 1251 positioned outside the kinase domain of IGF-IR [1618]. In human prostate cancer cells, blockade of IGF-IR expression by antisense cRNA inhibits proliferation and invasion and leads to an enhanced rate of spontaneous apoptosis [19]. However, apoptotic death was not observed when investigating the capacity of exogenous INTS6/DICE1 to induce the fragmentation of genomic DNA in prostate cancer cells. This suggested that DICE1 protein inhibits clonogenic cancer cell growth by bypassing an immediate apoptotic response. In agreement with this hypothesis, we were able to show that DICE1 reexpression in androgen-independent prostate cancer cells induced cell arrest in the G1 phase of the cell cycle identifying a molecular mechanism by which DICE1 could limit prostate cancer cell growth.

INTS6/DICE1 has been proposed to be a distant member of the DEAD box containing helicase superfamily II $[3,8]$. In this context, DICE1 protein has been recently identified as subunit 6 (INTS6) of the multi-protein Integrator complex involved in RNAPII-dependent transcription and processing of small nuclear RNA [9]. It now appears that modification in the expression level of INTS6/DICE1 could alter multi-protein complexes and consequently the gene expression profile in these cells. In prostate cancer with down-regulated INTS6/DICE1 expression, its exogenous expression may result in reassembly of DICE1 containing multi-protein complexes thus affecting distinct signaling pathways. Both IGF-1 receptor and Wnt signaling are fundamental pathways in tissue and organ development. Cross-talk between IGF-IR and Wnt signaling has been previously recognized during epithelium to mesenchymal transition as well as in Wnt-1/PTEN double transgenic mice $[20,21]$. A possible involvement of INTS6/ DICE1 in growth arrest induction by serum and growth factor withdrawal and contact inhibition may also be inferred from the observation that INTS6/DICE1 is one of the primary target genes of C/EAP $\delta[10]$. In fact, aberrantly activated Wnt signaling has also been implicated in prostate tumorigenesis and inhibition of the Wnt pathway in PC3 cells resulted in decreased colony formation in soft agar and in vivo tumor growth [22]. 


\section{Conclusion}

The results obtained in this study link DICE1 function to fundamental pathways involved in cell cycle regulation and cell-cell communication. Understanding DICE1 modes of action as it relates specifically to its regulatory properties on the Wnt signaling pathway will provide novel insights in support of a role for DICE1 protein in prostate cancer progression and may potentially lead to development of improved therapeutic approaches to prostate cancer.

\section{Methods}

Cell Lines

Human immortalized normal prostate cells RWPE-1 (American Type Culture Collection; ATCC) were grown in keratinocyte serum-free medium (Invitrogen, Carlsbad, CA) supplemented with $25 \mu \mathrm{g} / \mathrm{ml}$ bovine pituitary extract and $5 \mathrm{ng} / \mathrm{ml}$ epidermal growth factor. Human prostate cancer cells LNCaP, DU145, PC3 and PC3-ml were grown in RPMI 1640 medium supplemented with $10 \%$ fetal calf serum (HyClone, Perbio Science, Erembodegem-Aalst, Belgium) and $1 \%$ penicillin/streptomycin mix (Sigma, Taufkirchen, Germany). Paired cancer/normal human prostate cell lines, CPTX1532 and NPTX1532, were generated from patient undergoing radical prostatectomy and established by immortalization after micro-dissection of primary tumor cells and adjacent normal tissue respectively [14]. NPTX1532 and CPTX1532 cell lines were cultured in keratinocyte serum-free medium, $25 \mu \mathrm{g} / \mathrm{ml}$ bovine pituitary extract, $5 \mathrm{ng} / \mathrm{ml}$ epidermal growth factor, $2 \mathrm{mM}$ L-Glutamine, $10 \mathrm{mM}$ HEPES, $50 \mathrm{ng} / \mathrm{ml}$ gentamicin sulphate (all from Invitrogen, Carlsbad, CA), 5\% heat inactivated fetal bovin serum (BioWhitacker, Rockville, MD), 2.5\% penicillin/streptomycin mix (CellGro) and $0.5 \mu \mathrm{g} / \mathrm{ml}$ fungizone (CellGro). For transfection, prostate cells $\left(1 \times 10^{5}\right)$ were seeded in $35 \mathrm{~mm}$ culture dish and incubated overnight at $37^{\circ} \mathrm{C}$. The cells were then transfected for 4 hours with $4 \mu \mathrm{g}$ pDICE1-EGFP expression plasmid [13] or pEGFP control plasmid (Clontech) by using the CLONfectin kit (Clontech) following the recommended protocol. The transfection efficiencies were evaluated by counting the EGFP-positive cells under an inverted fluorescent microscope (Axiovert 25CFL, Zeiss, Göttingen, Germany), and reporting this number to the total number of cells (regular light).

\section{RNA isolation and Northern Blot analysis}

BALB/c3T3 mouse cells were infected with retroviral particles containing either the full length DICE1 cDNA or no insert. The retroviral packaging line Phoenix (provided by Dr. Gary Nolan at Stanford University) was used for viral transduction studies [23]. Cells were selected in $1 \mu \mathrm{g} / \mathrm{ml}$ puromycin for 3 days. Total RNA was isolated following the guanidinium isothiocyanate method of Chomczynski and Sacchi [24]. Northern blot analysis was carried out using $10 \mathrm{mg}$ of total RNA in glyoxal agarose gels. Size fractionated RNA was transferred to nylon filters electrophoretically in $1 \times$ Tris Acetate EDTA buffer (TAE). Probes were labeled by random priming and hybridization was carried out using a solution of $7 \%$ SDS, $0.25 \mathrm{M} \mathrm{Na}_{3} \mathrm{PO}_{4}, 5.6 \mathrm{mM}$ $\mathrm{Na}_{4} \mathrm{P}_{2} \mathrm{PO}_{7}, 2 \mathrm{mM}$ EDTA. Washing was carried out under standard conditions.

\section{Colony formation assay}

After transfection, prostate cells were incubated over 2-3 weeks in the presence of G418 antibiotic (Sigma) to allow colonies to develop. At the endpoint of the experiment, the medium was removed, the colonies washed in PBS and stained with $0.5 \%$ crystal violet (Sigma) in methanol. Each colony formation assay was carried out in triplicate and repeated at least three times. The working concentration of G418 $(380 \mu \mathrm{g} / \mathrm{ml}$ for PC3 and $240 \mu \mathrm{g} / \mathrm{ml}$ for DU145 cells) was defined as the lowest dose of antibiotic that kills $100 \%$ of non-transfected cells in 5-7 days from the start of G418 selection.

\section{Western blot analysis}

Cell extracts of EGFP and DICE1-EGFP transfected cells were produced by RIPA lysis and separated by SDS-polyacrylamide gel electrophoresis (SDS-PAGE) according to Harlow and Lane [25]. The gel was blotted on to a PVDF transfer membrane (PVDF Polyscreen, NEN Life Science Products, Boston, MA, USA) using a semi-dry blotting device (Trans-blot SD, BioRad, München, Germany). Immunodetection was carried out by using affinity-purified monoclonal anti-GFP antibody JL-8 (Living Colors, Clontech, Palo Alto, U.S.A) and chemiluminescence as described in [26].

\section{Cell cycle analysis}

For cell cycle analysis, prostate cells were trypsinized and washed with ice-cold PBS. Then cells were fixed with 70\% ice-cold ethanol for 1 hour, followed by incubation in freshly prepared nuclei staining buffer $(200 \mu \mathrm{g} / \mathrm{ml}$ RNase plus $20 \mu \mathrm{g} / \mathrm{ml}$ Propidium Iodide-PI in PBS) for 1 hour at $37^{\circ} \mathrm{C}$. Cell cycle histograms were generated after analysis of PI-stained cells by fluorescence-activated cell sorting (FACS) with a Becton Dickinson FACVantage SE Cell Sorter. For each sample, triplicates were performed and $>1$ $\times 10^{4}$ events were recorded. Histograms generated by FACS were analyzed by Cell Quest Software to determine the percentage of cells in each phase (G1-S-G2/M). Statistical evaluation of the data was done by paired Student's $t$ test using the SPSS 11.5 software for Windows. SE and P values are shown where appropriate.

Reverse transcription polymerase chain reaction (RT-PCR) Total RNA was isolated by using the RNeasy Mini kit (Qiagen GmBH, Hilden, Germany), following the manufacturer's recommendations. RNA $(2.5 \mu \mathrm{g})$ of PC3 and 
Table 2: Genes and corresponding primer sequences

\begin{tabular}{lllll}
\hline Gene Symbol & Forward Primer 5' $\rightarrow \mathbf{3}$ & Reverse Primer $\mathbf{5}$ ' $\rightarrow \mathbf{3}^{\prime}$ & Amplicon size (bp) & Annealing Temp. ( $\left.{ }^{\circ} \mathbf{C}\right)$ \\
\hline G3PDH & TGGTATCGTGGAAGGACTCA & ATGCCAGTGAGCTTCCCGTT & 188 & 58 \\
DICEI & TGCCCATCTTACTGTTCCTG & TCTTCGAAAGTGACCAGC & 169 & 58 \\
CXXC4 & TGCAAGAGGCTCATCAACTG & TCATTTCCAAATGCCTTGAA & 204 & 60 \\
CCNDI & AGGAACAGAAGTGCGAGGAG & GGCGGATTGGAAATGAACT & 394 & 60 \\
TCF7LI & ACGAGCTGATCCCCTTCC & TGACCTCGTGTCCTTGACTG & 400 & 60
\end{tabular}

DU145 cells were converted to cDNA by SuperScript III Reverse Transcriptase, using a mixture of Oligo dT $(0.25$ $\mu \mathrm{g})$ and Random Primer $(0.5 \mu \mathrm{g}$; all from Invitrogen, Carlsbad, CA, USA) in a volume of $11 \mu \mathrm{l}$ RNase-free water. Gene expression (Table 1) was quantified in triplicate with the iCycler and MyIQ amplifiers (Bio-Rad) using a SYBR-Green Supermix kit as recommended by the supplier (Bio-Rad). The real-time PCR was performed with primers and annealing temperatures described in table 2; expression of each of the INTS6/DICE1 target genes was quantified in three distinct batches of transfection.

\section{$R T^{2}$ Profiler PCR array system}

The expression of 84 genes related to human Wnt signaling pathway was analyzed in PC3 cells by quantitative real-time PCR using RT2 ${ }^{2}$ Profiler PCR Array technology (SABiosciences, Frederick, MD, USA). The provided Master Mix, containing dNTP's, polymerase, $\mathrm{MgCl}_{2}$ and SYBRGreen, and the cDNA were used as described by the manufacturer. The RT-PCR reaction was performed in the $\mathrm{iCy}$ cler (Bio-Rad). For data analysis $\mathrm{Ct}$ values were used for the gene of interest and the housekeeping gene glyceraldehyde-3-phosphate dehydrogenase (G3PDH). The relative quantification of gene expression was determined using the $2^{-\Delta \Delta \mathrm{C} T}$ method as described by Livak and Schmittgen [27].

\section{Competing interests}

The authors declare that they have no competing interests.

\section{Authors' contributions}

SF performed transfection, colony formation, apoptosis and necrosis assays, analyzed data and wrote the manuscript. JH and AW performed RT-PCR analysis, MS performed Western blot analysis, CS performed Northern blot analysis, MHS and SF performed cell cycle analysis, TN analyzed data and wrote the manuscript, IW constructed plasmids, conceived the project, analyzed data and wrote the manuscript. All authors read and approved the manuscript to be submitted for publication.

\section{Acknowledgements}

We thank Prof. P. Wieacker for helpful support to get this project started and E. Berger and J. Seger for technical assistance. This work was performed with the financial help of the South Plains Foundation, Lubbock, TX (SF).

\section{References}

I. Pienta KJ, Bradley D: Mechanisms underlying the development of andogen independent prostate cancer. Clin Cancer Res 2006, 12:1665-|67|.

2. Wieland I, Arden KC, Michels D, Klein-Hitpass L, Böhm M, Viars CS, Weidle UH: Isolation of DICEI: A gene frequently affected by LOH and down-regulated in lung carcinomas. Oncogene 1999 , I 8:4530-4537.

3. Wieland I, Röpke A, Stumm M, Sell C, Weidle UH, Wieacker PF: Molecular characterization of the DICEI (DDX26) tumor suppressor gene in lung carcinoma cells. Oncol Res 200I, I 2:49|-500

4. Li WJ, Hu N, Su H, Wang C, Goldstein AM, Wang Y, Emmert-Buck MR, Roth MJ, Guo WJ, Taylor PR: Allelic loss on chromosome $13 q \mid 4$ and mutation in deleted in cancer I gene in esophageal squamous cell carcinoma. Oncogene 2003, 22:3|4-318.

5. Röpke A, Buhtz P, Böhm M, Seger J, Wieland I, Allhoff EP, Wieacker PF: Promoter CpG hypermethylation and down-regulation of DICEI expression in prostate cancer. Oncogene 2005, 24:6667-6675.

6. Hernández M, Papadopoulos N, Almeida TA: Absence of mutations in DICEIIDDX26 gene in human cancer cell lines with frequent |3q|4 deletions. Cancer Genet Cytogenet 2005, 163:91-92.

7. Cancer Genome Project as of 06/2009 [http:/l www.sanger.ac.uk]

8. Whittaker CA, Hynes RO: Distribution and evolution of von Willebrand/Integrin A domains: Widely dispersed domains with roles in cell adhesion and elsewhere. Mol Biol Cell 2002, I3:3369-3387.

9. Baillat D, Hakimi M-A, Näär AM, Shilatifard A, Cooch N, Shiekhatter $\mathrm{R}$ : Integrator, a multiprotein mediator of small nuclear RNA processing, associates with the C-terminal repeat of RNA polymerase II. Cell 2005, I23:265-276.

10. Zhang Y, Liu T, Yan P, Huang T, DeWille J: Identification and characterization of CCAAT enhancer binding proteindelta $(\mathrm{C} /$ EBPdelta) target genes in $\mathbf{G}_{0}$ growth arrested mammary epithelial cells. BMC Mol Biol 2008, 9:83.

II. Rozenblatt-Rosen O, Nagaike T, Francis JM, Kaneko S, Glatt KA, Hughes CM, LaFramboise T, Manley JL, Meyerson M: The tumor suppressor Cdc73 functionally associates with CPSF and CstF 3' mRNA processing factors. Proc Natl Acad Sci USA 2009, 106:755-760

12. Hoff HB III, Tresini M, Li S, Sell C: DBI-I, a novel gene related to the Notch family, modulates mitogenic response to insulinlike growth factor I. Exp Cell Res 1998, 238:359-370.

13. Wieland I, Sell C, Weidle UH, Wieacker P: Ectopic expression of DICEI suppresses tumor cell growth. Oncol Rep 2004, 12:207-2II.

14. Bright RK, Vocke CD, Emmert-Buck MR, Duray PH, Solomon D, Fetsch P, Rhim JS, Linehan WM, Topalian SL: Generation and genetic characterization of immortal human prostate epithelial cell lines derived from primary cancer specimens. Cancer Res 1997, 57:995-1002.

15. Zi X, Simoneau AR, Hope $\mathrm{C}$, Xie J. Holcombe RF, Hoang BH: Expression of Frzb/secreted frizzled-related protein 3, a secreted Wnt antagonist, in human androgen-independent prostate cancer PC-3 cells suppresses tumor growth and cellular invasiveness. Cancer Res 2005, 65:9762-9770.

16. Hongo A, D'Ambrosio C, Miura M, Morrione A, Baserga R: Mutational analysis of the mitogenic and transforming activities of 
the insulin-like growth factor I receptor. Oncogene 1996, 1 2: $1231-1238$

17. O'Connor R, Kaufmann-Zeh A, Liu Y, Lehar S, Evan GI, Baserga R: Identification of domains of the insulin-like growth factor I receptor that are required for protection from apoptosis. Mol Cell Biol 1997, 17:427-435.

18. Brodt P, Fallavollita L, Khatib A-M, Samani AA, Zhang D: Cooperative regulation of the invasive and metastatic phenotypes by different domains of the type $I$ insulin-like growth factor receptor $\beta$ subunit. J Biol Chem 200I, 276:33608-336I5.

19. Grzmil M, Hemmerlein B, Thelen P, Schweyer S, Burfeind P: Blockade of the type I IGF receptor expression in human prostate cancer cells inhibits proliferation and invasion, up-regulates IGF binding protein-3, and suppresses MMP-2 expression. J Pathol 2004, 202:50-59.

20. Morali OG, Delmas V, Moore R, Jeanny C, Thiery JP, Larue L: IGF-II induces rapid $\beta$-catenin relocation to the nucleus during epithelium to mesenchyme transition. Oncogene 200I, 20:4942-4950.

21. Zhao H, Cui Y, Dupont J, Sun H, Hennighausen L, Yakar S: Overexpression of the tumor suppressor gene phosphatase and tensin homologue partially inhibits Wnt-I-induced mammary tumorigenesis. Cancer Res 2005, 65:6864-6873.

22. Hino SI, Kishida S, Michiue T, Fukui A, Sakamoto I, Takada S, Asashima M, Kikuchi A: Inhibition of the Wnt signaling pathway by Idax, a novel Dvl-binding protein. Mol Cell Biol 200I, $21: 330-342$.

23. Pear WS, Nolan GP, Scott ML, Baltimore D: Production of hightiter helper-free retroviruses by transient transfection. Proc Natl Acad Sci USA 1993, 90:8392-8396.

24. Chomczynski P, Sacchi N: Single-step method of RNA isolation by acid guanidinium thiocyanate-phenol-chloroform extraction. Anal Biochem 1987, 162:156-159.

25. Harlow E, Lane D: Antibodies: A Laboratory Manual Cold Spring Harbor, Cold Spring Harbor Laboratory Press; 1988.

26. Drewniok C, Wienrich BG, Schön M, Ulrich J, Zen Q, Telen MJ, Hartig RJ, Wieland I, Gollnick H, Schön MP: Molecular interactions of B-CAM (Basal-Cell Adhesion Molecule) and laminin in epithelial skin cancer. Arch Dermatol Res 2004, 296:59-66.

27. Livak KJ, Schmittgen TD: Analysis of relative gene expression data using real-time quantitative $P C R$ and the $2-\Delta \Delta C T$ Method. Methods 200I, 25:402-408.

Publish with Bio Med Central and every scientist can read your work free of charge

"BioMed Central will be the most significant development for disseminating the results of biomedical research in our lifetime. "

Sir Paul Nurse, Cancer Research UK

Your research papers will be:

- available free of charge to the entire biomedical community

- peer reviewed and published immediately upon acceptance

- cited in PubMed and archived on PubMed Central

- yours - you keep the copyright
BioMedcentral 